\title{
Tabes Dorsalis
}

National Cancer Institute

\section{Source}

National Cancer Institute. Tabes Dorsalis. NCI Thesaurus. Code C35057.

A form of neurosyphilis characterized by slowly progressive degeneration of the spinal cord. Signs and symptoms include pain, ataxia, loss of coordination, personality changes, blindness, urinary incontinence, dementia, and degeneration of the joints. 